\title{
Gastric cancer surgery: historical background and perspective in Western countries versus Japan
}

\author{
Chun-Dong Zhang, Hiroharu Yamashita, Yasuyuki Seto \\ Department of Gastrointestinal Surgery, Graduate School of Medicine, University of Tokyo, Tokyo, Japan \\ Contributions: (I) Conception and design: CD Zhang, H Yamashita; (II) Administrative support: Y Seto; (III) Provision of study materials or patients: \\ H Yamashita; (IV) Collection and assembly of data: CD Zhang, H Yamashita; (V) Data analysis and interpretation: CD Zhang, H Yamashita; (VI) \\ Manuscript writing: All authors; (VII) Final approval of manuscript: All authors. \\ Correspondence to: Hiroharu Yamashita, MD, PhD. Department of Gastrointestinal Surgery, Graduate School of Medicine, University of Tokyo, \\ Tokyo, Japan. Email: hiroharu.yamashita@gmail.com.
}

\begin{abstract}
Gastrectomy plus D2 lymphadenectomy plays a decisive role in the management of resectable gastric cancer in Japan. Before recent advances in chemotherapy, Japanese surgeons considered that extensive surgery involving extended lymphadenectomy with combined resection of neighboring organ(s) was required to eliminate any possible lymphatic cancer spread and improve patient survival. This approach differs radically from that in Western countries, which aim to improve survival outcomes by multidisciplinary approaches including perioperative chemotherapy and/or radiotherapy with limited lymph node dissection. However, a randomized controlled trial conducted in Japan found that more extensive lymphadenectomy including the para-aortic lymph nodes provided no survival benefit over D2 lymphadenectomy. Splenic hilum dissection with splenectomy also failed to show superiority over the procedure without splenectomy in patients with proximal gastric cancer, except in cases with tumor invasion of the greater curvature. Furthermore, bursectomy recently demonstrated similar outcomes to omentectomy alone. Although "D2 lymphadenectomy" as carried out in Japan contributes to low local recurrence rates and good survival outcomes, the results of randomized controlled trials have led to a decreased extent of surgical resection, with no apparent adverse effects on survival outcome. Notably, gastrectomy with D2 dissection has tended to become acceptable for advanced gastric cancer in Western countries, based on the latest results of the Dutch D1D2 trial. Differences in surgical practices between the West and Japan have thus lessened and procedures are becoming more standardized. Japanese D2 lymphadenectomy for advanced gastric cancer is evolving toward more minimally invasive approaches, while consistently striving to achieve the optimal surgical extent, thereby promoting consensus with Western counterparts.
\end{abstract}

Keywords: Gastric cancer; surgery; lymphadenectomy; Western countries; Japan

Submitted Jul 29, 2019. Accepted for publication Aug 08, 2019.

doi: $10.21037 /$ atm.2019.08.48

View this article at: http://dx.doi.org/10.21037/atm.2019.08.48

\section{Introduction}

Despite a substantial decline in its global incidence, gastric cancer remains the fifth most frequently diagnosed cancer and the third leading cause-related deaths worldwide (1), with an estimated 1,033,701 newly diagnosed cases and 782,685 related deaths in 2018 (2). The incidence rates of gastric cancer in both sexes are highest in Eastern Asia, especially Mongolia, the Republic of Korea, and Japan (2). The first gastrectomy was performed successfully by Billroth in 1881, and radical gastrectomy remains the first choice for achieving a cure in patients with resect able gastric cancer (3-5). Radical gastrectomy involves eradication of the primary lesion with a satisfactory resection margin (R0), together with radical dissection of regional lymph nodes. 
However, surgeons have also explored more extensive surgeries aiming to eliminate any possible lymphatic spread by applying extended lymphadenectomy, such as superextended (D3) lymphadenectomy (6-12) or standardized extended (D2) lymphadenectomy plus para-aortic nodal dissection (PAND) (13-17), together with combined resection, such as prophylactic splenectomy (18-24) or bursectomy (25-30). Radical gastrectomy with D2 dissection has been the standard procedure for locally advanced gastric cancer (AGC) in Japan since 1961 (5,31-36). Gastrectomy with $\mathrm{D} 2$ dissection has also recently tended to become acceptable for AGC in Western countries, in light of the latest 15-year follow-up results of the Dutch D1D2 trial, which showed significant survival benefits of D2 over standardized limited (D1) lymphadenectomy (36).

Rapid advances in surgical oncology worldwide have significantly improved the safety of gastrectomy. The 30-day post-gastrectomy mortality rates for patients with gastric cancer in Western countries over the last two decades have ranged from $1.9 \%$ to $5.1 \%$ (10,37-39), with postoperative in-hospital mortality rates of $5.8 \%$ to $9.8 \%(36,40-42)$. In contract, the overall operative mortality rates in Japan from 2011 to 2012 were $2.3 \%$ after total gastrectomy (43) and $1.07 \%$ after distal gastrectomy (44), and the equivalent 30 -day mortality rates were $0.9 \%$ (43) and $0.45 \%$ (44), respectively, which appeared to indicate better outcomes than in Western countries (36-38,40-42,45). However, there remains scope for further global improvements in the safety of gastric cancer surgery. According to the theory of epistemology, involving practice, understanding, repractice, and re-understanding, the preferred extent of gastric resection and lymph node dissection has experienced a pendulum-like phenomenon, from narrowed to extended, and then narrowed again, gradually rationalized from the original bias. Here, we review and compare the historical backgrounds and perspectives of gastric cancer surgeries in Western countries and Japan.

\section{Epidemiology}

Gastric cancer was estimated to account for over a million newly diagnosed cases and nearly 783,000 deaths (equating to 1 in 12 deaths) worldwide in 2018 (2), largely due to population aging and growth (46). One in 27 men and 1 in 68 women will develop gastric cancer before the age of 79 years, with the highest and lowest odds for men in middle (1 in 15) and low-middle sociodemographic index
(SDI) countries (1 in 48), respectively, and the highest and lowest odds for women in low (1 in 58) and low-middle (1 in 83 ) SDI countries, respectively (46). The mortality rates of gastric cancer in men [calculated as agestandardized mortality rate per 100,000 (ASR)] ranged from 4.2 in Switzerland to 24.6 in the Russian Federation among Europe countries, 2.6 in the USA, 25.3 in the Republic of Korea, and 21.0 in Japan during the period 2005-2009 (47). The ASRs for women ranged from 1.9 in France to 10.1 in the Russian Federation, 1.3 in the USA, 9.2 in the Republic of Korea, and 8.0 in Japan, over the same period (47).

Non-cardia gastric cancer (NCGC) is more frequent than cardia gastric cancer (CGC) in most countries, with an estimated 691,000 cases of NCGC and 260,000 cases of CGC worldwide in 2012 (48). Approximately $90 \%$ of new NCGC cases were considered to be associated with Helicobacter pylori (H. pylori) infection (49). However, the incidence of NCGC has been declining worldwide over the last half century, as a result of the decreased prevalence of $H$. pylori and improved food-storage conditions (2). In contract, the incidence of CGC has been steadily increasing, particularly in high income countries, following the distribution characteristics of esophagus cancer in developed countries $(50,51)$, where the incidence rates of Barrett's esophagus are higher than in Eastern countries. The proportion of men with CGC among all gastric cancer cases ranged from $11.6 \%$ in Belarus to $72.0 \%$ in Finland, and was higher in Northern and Central Europe compared with Southern and Eastern Europe (47). Notably, the incidence of CGC remained unchanged in the USA, according to a recent report (52).

Although the incidence of gastric cancer was expected to follow a decreasing trend owing to a lower incidence of $H$. pylori infection among the younger generation in Japan (53), its incidence has remained the highest of all types of cancers in both males and females (male-to-female ratio >2:1) (54). Considering this high incidence, a cost-effective screening program was initiated to increase the rate of early detection of gastric cancer in Japan. Approximately $48.8 \%$ cases were diagnosed with early gastric cancer and $80 \%$ of tumors were located in the middle or lower third of the stomach (54-56), with improvements attributed to the screening program (57-62). Notably, the 5-year overall survival rates in Japan were reported to be about $70.0 \%(54,56)$, and the good survival outcomes were considered to be least partly attributable to the large proportion of patients diagnosed at an early stage (63). 
Table 1 Standards of D1 and D2 lymphadenectomy in Western countries and Japan

\begin{tabular}{|c|c|c|c|c|c|}
\hline Guidelines, year & Country/Region - & \multicolumn{2}{|c|}{ D1 lymphadenectomy } & \multicolumn{2}{|c|}{ D2 lymphadenectomy } \\
\hline ESMO, 2016 (4) & Europe & ND & No. $1,2,3,4,5,6$ & ND & No. $1,2,3,4,5,6,7,8,9,11$ \\
\hline NCCN, 2017 (3) & USA & ND & No. $1,2,3,4,5,6$ & ND & No. $1,2,3,4,5,6,7,8,9,10,11$ \\
\hline JGCA, 2017 (5) & Japan & Total gastrectomy & No. $1,2,3,4,5,6,7$ & Total gastrectomy & $\begin{array}{l}\text { No. } 1,2,3,4,5,6,7,8 a, 9,10 \\
11 p, 11 d, 12 a\end{array}$ \\
\hline
\end{tabular}

ESMO, European Society for Medical Oncology; NCCN, National Comprehensive Cancer Network; JGCA, Japanese Gastric Cancer Association; ND, no details; No. 1, right paracardial lymph node; No. 2, left paracardial lymph node; No. 3, perigastric lymph node along lesser curvature; No. 4sb, perigastric lymph node along greater curvature (left group, lymph node along left gastroepiploic artery and short gastric arteries); No. 4d, perigastric lymph node along greater curvature (right group, lymph node along right gastroepiploic artery); No. 4 , perigastric lymph node along greater curvature; No. 5, suprapyloric lymph node; No. 6, infrapyloric lymph node; No. 7, lymph node along left gastric artery; No. 8, lymph node along common hepatic artery; No. 8a, lymph node along common hepatic artery (anterosuperior group); No. 9, lymph node around celiac artery; No. 10, lymph node at splenic hilum; No. 11p, lymph node along proximal splenic artery; No. $11 \mathrm{~d}$, lymph node along distal splenic artery; No. 11, lymph node along splenic artery; No. 12a, lymph node in hepatoduodenal ligament (along hepatic artery).

\section{D1 and D2 lymphadenectomy}

The extent of lymph node dissection with radical gastrectomy has been extensively debated worldwide. According to the recent clinical practice guidelines of European Society for Medical Oncology (ESMO) for gastric cancer, D1 involves perigastric lymph nodes (LNs) of No. 1, 2, 3, 4, 5, 6 and D2 dissection involves LNs of No.1, 2, 3, 4, 5, 6, 7, 8, 9, 11 (4). In addition, based on the latest National Comprehensive Cancer Network (NCCN) guidelines, D1 involves LNs of No. 1, 2, 3, 4, 5, 6 and D2 dissection involves LNs of No. 1, 2, 3, 4, 5, 6, 7, 8, 9, 10, 11 (3). Notably, the Japanese Gastric Cancer Association has clearly identified the extent of systematic lymph node dissection with gastrectomy type. In total gastrectomy, D1 involves LNs of No.1, 2, 3, 4, 5, 6, 7 and D2 dissection involves LNs of No. 1, 2, 3, 4, 5, 6, 7, 8a, 9, 10, 11p, 11d, $12 \mathrm{a}(5,32)$. Whereas, in distal gastrectomy, D1 involves LNs of No. 1, 3, 4sb, 4d, 5, 6, 7 and D2 dissection involves LNs of No. 1, 3, 4sb, 4d, 5, 6, 7, 8a, 9, 11p, 12a (5,32) (Table 1).

Both the ESMO and NCCN guidelines did not clarify clear relations between gastrectomy types and extents of systematic lymph node dissection; furthermore, both classified No. 7 lymph node in D2 dissection (3,4). Japanese surgeons, on the other hand, have already changed No. 7 lymph node into D1 dissection for any type of gastrectomy, since the $3 \mathrm{rd}$ version of the Japanese gastric cancer treatment guidelines in 2011 (5,31,32). The nodal grouping based on the tumor location was abandoned because that it was too complicated to be accurately understood worldwide; notably, the lymph node stations to be dissected in D1 and D2 dissection have been defined according to gastrectomy type regardless of tumor location in Japan since then $(31,32)$.

\section{Surgery in Western countries}

The preferred extent of gastric resection has experienced a pendulum-like phenomenon, switching from narrowed to extended, and then narrowed again, gradually becoming rationalized. The first successful case of distal gastrectomy in the West was performed by Billroth in 1881, though the first patient to undergo distal gastrectomy with Billroth I type reconstruction only survived for 115 days. Schlatter et al. performed the first total gastrectomy in 1897, while Mikulicz was reported to be the first to successfully perform cardiectomy (64). Notably, they stressed the importance of studying the pathways of gastric cancer spread, and established the foundation of surgical therapy for gastric cancer as follows: direct infiltration of the submucosa and muscularis (operable), dissemination via the lymphatics (operable), transperitoneal spread with lesions involving the full thickness of the stomach wall (inoperable), and dissemination through the blood stream to distant organs (inoperable) (64). This period represented the dawn of gastric cancer surgery, attributed to Mikulicz's theory of lymphatic drainage of the stomach with removal of all 
palpable nodes, along with Billroth's contribution to gastric cancer surgery.

Groves et al. reported the first case of omentobursectomy in 1910 (65). They addressed the importance of complete removal of the great omentum by cutting through the peritoneum, which passes from the back of the omentum to the front of the transverse colon, followed by stripping the peritoneum off the upper surface of the transverse mesocolon to the front of the pancreas. Furthermore, they emphasized the need for a more systematic attempt to remove the whole of the associated lymphatic area (65). Although the 3-year survival rate was only $7.6 \%$, possibly due to incomplete lymphadenectomy, his theory nevertheless contributed to later lymphadenectomy practices.

During the period from 1940 to1960, many experts in the West reported extensive surgeries with combined resection of neighboring organs with the aim of improving patient survival (66-68); however, the postoperative morbidity and mortality rates were very high. Cattell et al. reported combined resection of the stomach and transverse colon in 1946 (69). In 1947, Pack et al. reported total gastrectomy for gastric cancer, with an operative mortality of $20-30 \%$ (70), followed later by a series of clinical studies of radical or palliative surgeries for gastric cancer (71-74). Brunschwig et al. performed the first gastrectomy with pancreatoduodenectomy (PD) for distal gastric cancer invading the head of pancreas in 1948 (66), and Appleby et al. introduced a combined procedure in 1953, including resection of the whole stomach, distal pancreas, spleen, and regional lymph nodes (75). Lawrence et al. reported 5-year survival rates before and after the application of extensive surgery of $21.6 \%$ from $1931-1950$, and $23.3 \%$ from 1951-1954 (68); however, no randomized controlled trial (RCTs) were available until 1985 to provide sufficient evidence for any strong recommendations.

Whether or not total gastrectomy could improve the survival of patents with distal gastric cancer thus remained to be validated in the West, and several studies comparing survival rates after total and subtotal gastrectomy for distal gastric cancer were conducted after 1970. McNeer et al. reported a better 5 -year survival rate following total gastrectomy (43.7\%) compared with subtotal gastrectomy (29.8\%) (76). A similar result was reported by LortatJacob et al., with total gastrectomy showing a higher 5-year overall survival rate but a higher postoperative mortality than subtotal gastrectomy (77). In contrast, however,
Gennari et al. in 1986 reported a higher 5-year survival rate after subtotal compared with total gastrectomy in patients with lymph node involvement (78). However, those were all retrospective studies with high risks of bias. Notable, the first global RCT comparing total versus subtotal gastrectomy for gastric antrum cancer was conducted in French in 1989 (79), and demonstrated no survival benefits of total over subtotal gastrectomy. A subsequent RCT by the Italian Gastrointestinal Tumor Study Group in 1999 also found no advantage of total gastrectomy over subtotal gastrectomy (80) (Table 2). It is therefore necessary to bear in mind the saying of Confucius, that "excess is just as bad as deficiency".

The issue of whether patients may benefit from D2 dissection remained controversial in Western countries (13,34-36). The United Kingdom Medical Research Council Gastric Cancer Surgical Trial (MRC, ST01) confirmed no survival advantages of D2 over D1 dissection $(40,81)$ (Table 2). Similarly, the Dutch D1D2 trial in the Netherlands demonstrated D2 dissection was associated with a higher risk of postoperative morbidity ( $43 \% v s .25 \%$; $\mathrm{P}<0.001)$ and mortality ( $10 \%$ vs. $4 \% ; \mathrm{P}=0.004)$ compared with $\mathrm{D} 1$ dissection, with no differences in overall survival rate after the 11 -year follow-up period (35\% vs. $30 \%$; $\mathrm{P}=0.53$ ) (33). Another RCT conducted by the Italian Gastric Cancer Study Group suggested that D2 dissection may only be a better choice only in patients with nodal metastases (45). However, more recent results of the Dutch D1D2 trial after a 15 -year follow-up period showed significant survival benefits of D2 over D1 dissection in terms of cancer-related death rate (48\% vs. 37\%), local recurrence (12\% vs. 22\%) and regional recurrence (13\% vs. 19\%) (36).

In light of those findings and the good survival outcomes after D2 dissection in Japan, gastrectomy with D2 dissection is becoming increasingly acceptable in Western countries. The latest National Comprehensive Cancer Network guidelines for gastric cancer stated that D2 dissection should be considered as a recommended but not a required procedure, nothing that the technical aspects of D2 dissection require a significant degree of training and expertise (3). In addition, the latest European Society for Medical Oncology guidelines for gastric cancer suggested that medically fit patients should undergo D2 dissection in specialized, high-volume centers in Western countries (4,82-84) (Table 2). However, further studies are still needed to determine if $\mathrm{D} 2$ dissection should become the standard procedure for gastric cancer patients in Western countries. 


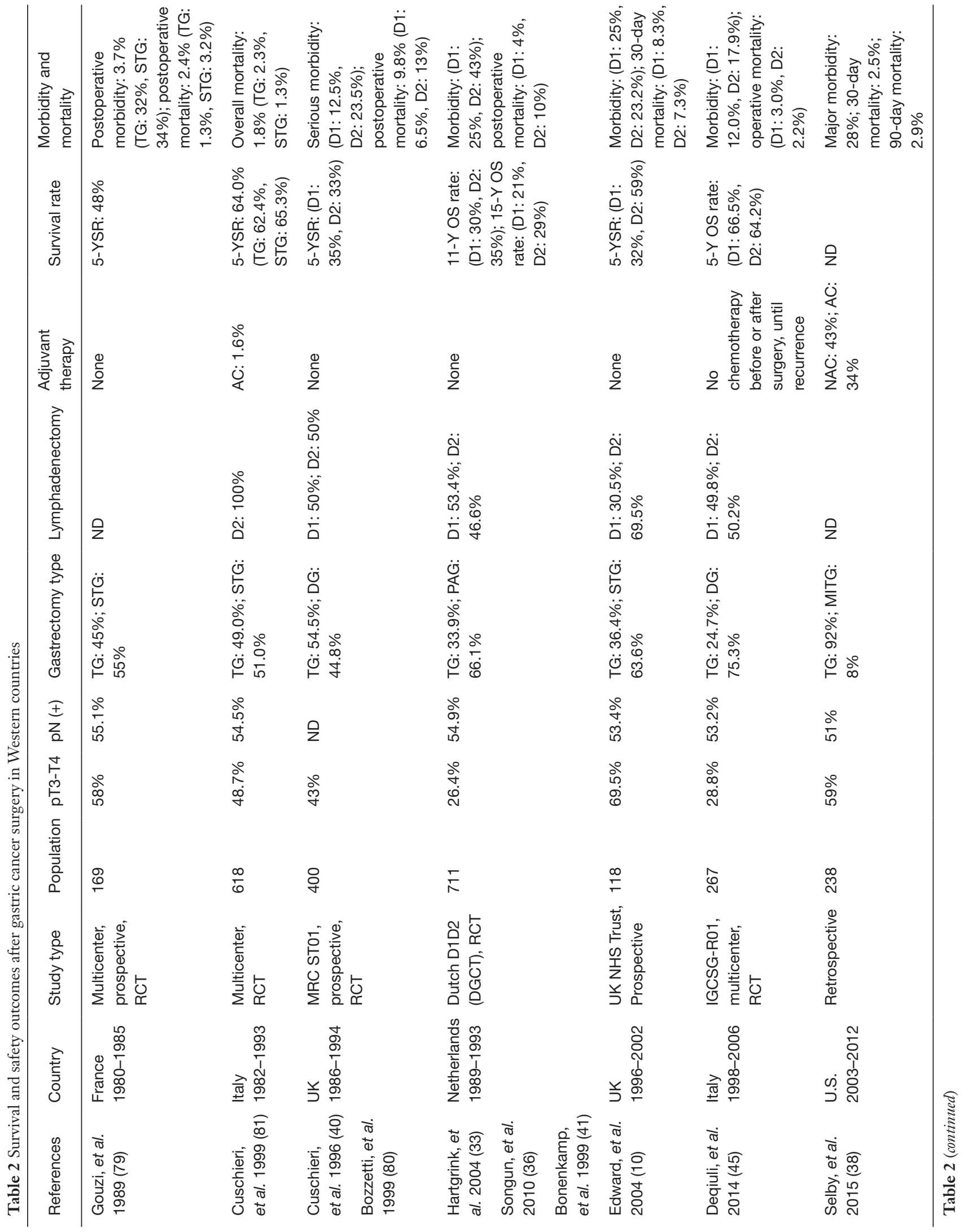




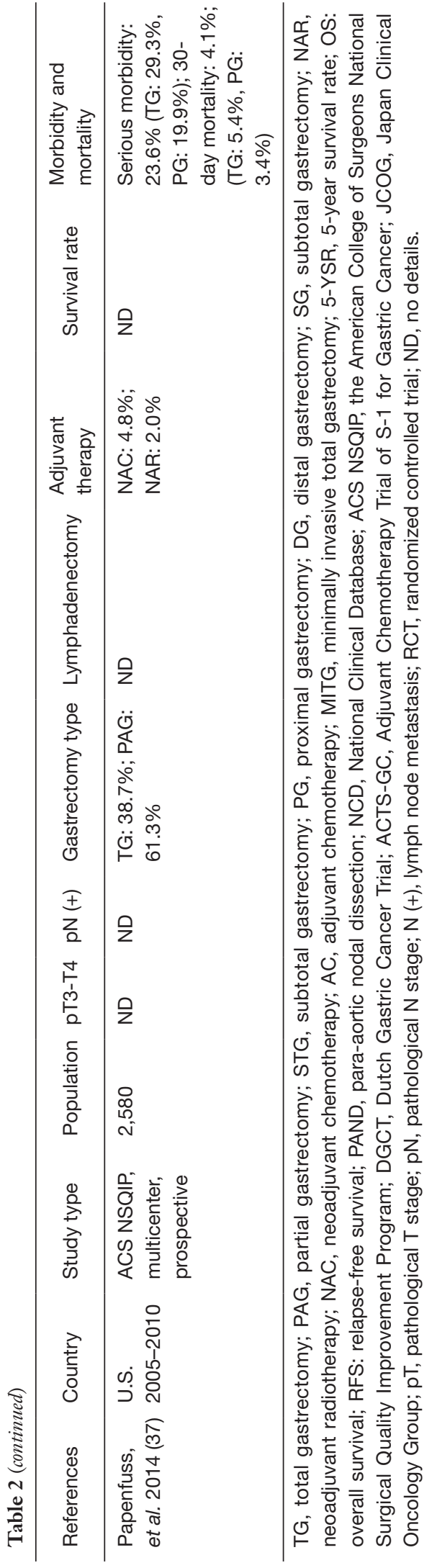

\section{Surgery in Japan}

The first successful case of distal gastrectomy in Japan was performed in 1897 by Kondo, a professor from the First Department of Surgery of Tokyo University Hospital (85), while the first case of total gastrectomy in Japan was reported by Miyake et al. in 1918. Based on the fact that nodal metastasis was the most frequent type of cancer spread, surgeons in Japan gradually focused on lymphadenectomy from around 1940, with the aim of eliminating any possible nodal metastasis and thus improving survival. Kuru et al. first stressed the use of systematic radical lymphadenectomy in 1935 (86), and Kajitani et al. in 1944 emphasized the importance of wide lymphadenectomy to eliminate any possible nodal metastasis (87).

Extended surgeries involving extended lymphadenectomy or combined resection of neighboring organs were subsequently performed to improve patient survival. Extended radical surgery with PD was first reported in Japan by Kajitani et al. in 1952, for the treatment of distal gastric cancer involving the head of pancreas (88). Jinnai et al. advocated the theory of systematic radical lymphadenectomy and stressed the use of extended lymphadenectomy in 1961 (89). Ohashi et al. reported 5-year survivors of gastric cancer treated with PAND in 1976 (90) and Kajitani et al. introduced left upper abdominal quadrant evisceration for proximal advanced cancer in 1981 (91). In 1989, Ohta et al. stressed the value of total gastrectomy combined with pancreaticosplenectomy for middle gastric cancer (92). However, the lack of evidence from RCTs meant that the role of extended surgery in improving patient survival remained controversial until the past two decades.

D2 dissection plus PAND has not demonstrated any survival benefits over D2 dissection alone. The Japan Clinical Oncology Group (JCOG) conducted a multicenter, RCT (JCOG9501) and showed that D2 dissection plus PAND could be performed safely in patients with low operative risk by specialized surgeons, but no significant improvement in survival was observed (13). Notably, the final results of JCOG 9501 in 2008 confirmed that D2 dissection plus PAND (No.16a2, b1) did not improve 5-year overall survival [hazard ratio (HR), 1.03, 95\% confidence interval (CI), 0.77-1.37; $\mathrm{P}=0.85$ ] or recurrence-free survival (HR, 1.08, 95\% CI, 0.83-1.42; $\mathrm{P}=0.56$ ) in patients with curable gastric cancer, compared with D2 dissection alone (16). 
Pancreatic resection frequently resulted in pancreaticjuice leakage, subphrenic abscess, and postoperative diabetes, leading Maruyama et al. to develop pancreaspreserving surgery in 1979. They also demonstrated gastric cancer tumors only invaded the pancreas directly, rather than by metastasis to the pancreas. Pancreas-preserving surgery proved superior to pancreas resection in terms of operative mortality, hospital mortality, surgical morbidity, and 5 -year survival rate (93). Accordingly, lymphatic channels from the stomach did not flow into the pancreas parenchyma, and surgeons could remove the spleen, splenic artery, fatty connective tissues, and lymph nodes completely without dissecting the pancreas parenchyma or splenic vein (93). The results of an RCT conducted by Furukawa et al. in 2000 also supported the superiority of pancreaspreserving surgery (total gastrectomy with dissection of lymph nodes along the splenic artery) over pancreas resection in terms of surgical risk and postoperative glucose tolerance (94).

Splenic hilum nodal dissection with splenectomy showed no benefits over the procedure without splenectomy in patients with proximal gastric cancer (24). A recent, multi-institutional, RCT (JCOG0110) conducted in 505 patients from 36 institutions in Japan (24) confirmed that the addition of splenectomy was associated with higher morbidity and blood loss, but similar operation time. The 5 -year survival rates were $75.1 \%$ in the splenectomy group and $76.4 \%$ in the spleen preservation groups $(\mathrm{P}=0.025)$. Splenectomy thus increase operative morbidity without improving survival, and should therefore be avoided in patients undergoing total gastrectomy for proximal gastric cancer, unless it invades the greater curvature.

The role of bursectomy in preventing peritoneal metastasis has long been controversial. One RCT found no survival benefit but a high risk of morbidity for bursectomy in patients with cT3-4a gastric cancer (95). In addition, a recent, phase 3 RCT (JCOG1001) that enrolled 1,204 patients from 57 hospitals in Japan confirmed that bursectomy had no survival advantages over non-bursectomy, indicating that D2 dissection with omentectomy alone should be the recommended surgery for resectable cT3-4a gastric cancer in Japan (96). Furthermore, the Japanese Gastric Cancer Association (JGCA) recommended gastrectomy with D2 dissection as the standard surgical procedure for potentially curable gastric cancer (clinical stage $\geq \mathrm{cT} 2$ and/or cN+) in Japan (5).
Japanese surgeons had long believed that gastric cancer patients should receive extensive surgery, including extended lymphadenectomy or with combined resection of neighboring organs, to eliminate any possible nodal spread and thus improve patient survival. In 1991, 67.6\% of Japanese patients with gastric cancer underwent D2 dissection, $9.9 \%$ underwent D3 or D4 dissection, 30.7\% received total gastrectomy, and $30.3 \%$ received combined resection of neighboring organs (1,515 splenectomy, 726 pancreatomy) (56). This situation remained unchanged until the introduction of the new anticancer agent, S-1, for advanced gastrointestinal cancer in Japan in 1999, which proved effective against advanced or recurrent gastrointestinal cancer, with generally mild toxicities and no toxic deaths $(97,98)$ (Table 3). Since then, rapid advances in chemotherapy (95,99-111), including targeted therapy (112-114), have led Japanese experts gradually to adopt the Western strategy of improving survival by multidisciplinary approaches, including neoadjuvant or adjuvant chemotherapy. The differences in surgical practice for gastric cancer between the West and Japan have thus gradually lessened, and are becoming increasingly standardized.

\section{Future perspectives}

Surgical therapy for gastric cancer originated in Western countries and developed rapidly in Japan. Japanese experience suggests that screening programs should be implemented to improve the early detection of gastric cancer, particularly in high incidence areas. Surgical safety and maximizing the probability of a cure should remain the highest priorities; however, chemotherapy, along with genetic diagnosis and targeted therapy, are gaining importance worldwide. Further studies are needed to consider how best to balance the combinations among neoadjuvant or adjuvant chemotherapy and surgery in patients with gastric cancer. Attempts should also be made to reduce the incidence of gastric cancer, in addition to taking account of quality of life and economic costs. Recent developments and modifications of minimally invasive techniques have also attracted increasing interest (115-118), especially in Japan (119-122). Overall, international cooperation between Western and Eastern countries should be encouraged to establish global standards for the diagnosis and therapy of gastric cancer. 


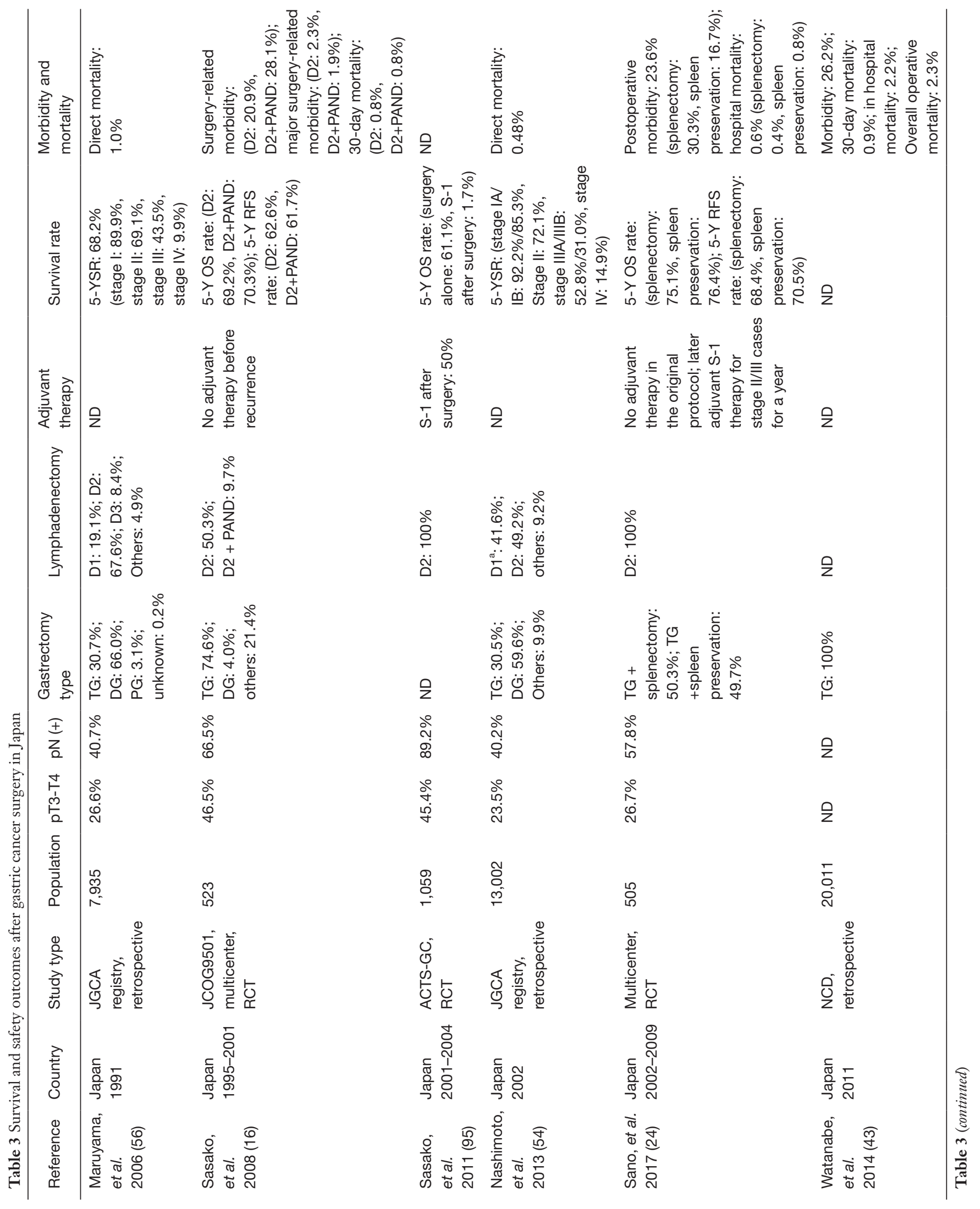




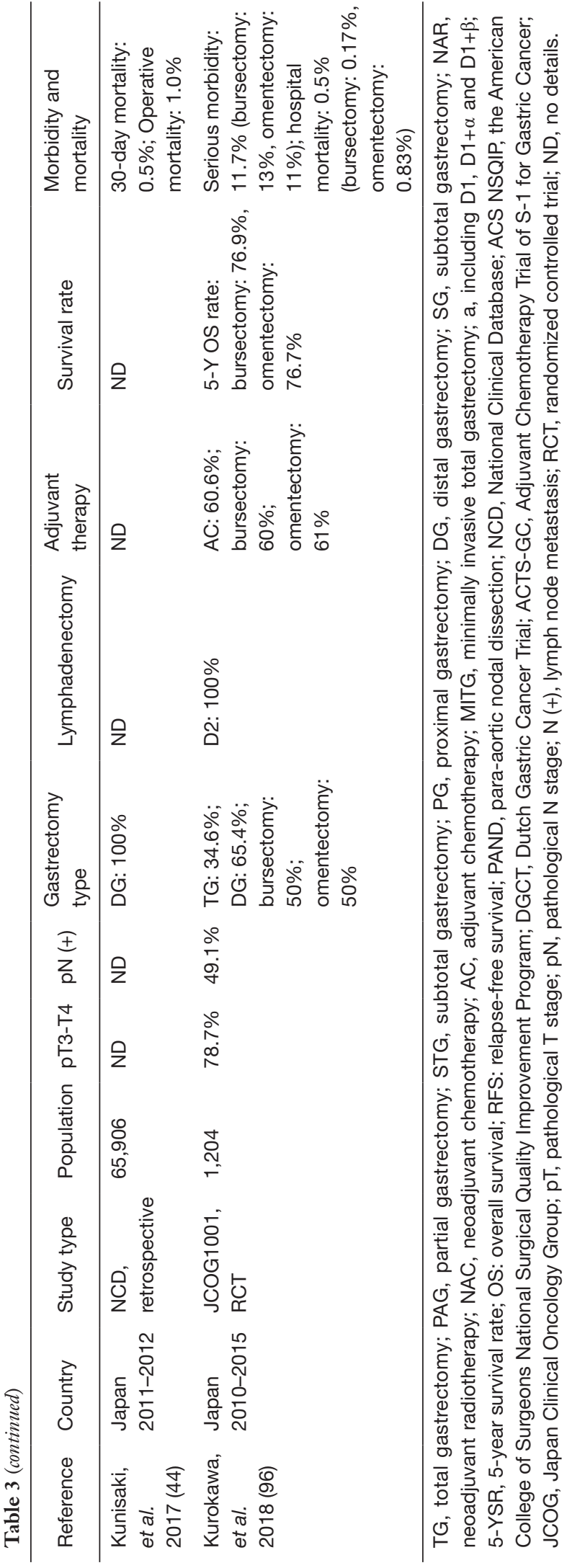

\section{Acknowledgments}

Funding: We thank the financial support from Japan China Sasakawa Medical Fellowship, and the China Scholarship Council (201908050148).

\section{Footnote}

Conflicts of Interest: The authors have no conflicts of interest to declare.

Ethical Statement: The authors are accountable for all aspects of the work in ensuring that questions related to the accuracy or integrity of any part of the work are appropriately investigated and resolved.

\section{References}

1. Ferlay J, Soerjomataram I, Dikshit R, et al. Cancer incidence and mortality worldwide: Sources, methods and major patterns in GLOBOCAN 2012. Int J Cancer 2015;136:E359-86.

2. Bray F, Ferlay J, Soerjomataram I, et al. Global cancer statistics 2018: GLOBOCAN estimates of incidence and mortality worldwide for 36 cancers in 185 countries. CA Cancer J Clin 2018;68:394-424.

3. Ajani JA, D'Amico TA, Almhanna K, et al. Gastric Cancer, Version 3.2016, NCCN Clinical Practice Guidelines in Oncology. J Natl Compr Canc Netw 2016;14:1286-312.

4. Smyth EC, Verheij M, Allum W, et al. Gastric cancer: ESMO Clinical Practice Guidelines for diagnosis, treatment and follow-up. Ann Oncol 2016;27:v38-49.

5. Japanese Gastric Cancer, A., Japanese gastric cancer treatment guidelines 2014 (ver. 4). Gastric Cancer 2017;20:1-19.

6. Adachi Y, Mimori K, Mori M, et al. Morbidity after D2 and D3 gastrectomy for node-positive gastric carcinoma. J Am Coll Surg 1997;184:240-4.

7. Pacelli F, Doglietto GB, Alfieri S, et al. Avoiding pancreatic necrosis following pancreas-preserving D3 lymphadenectomy for gastric cancer. Br J Surg 1998;85:125-6.

8. Maeta M, Yamashiro H, Saito H, et al. A prospective pilot study of extended (D3) and superextended paraaortic lymphadenectomy (D4) in patients with T3 or T4 gastric cancer managed by total gastrectomy. Surgery 1999;125:325-31.

9. Günther K, Horbach T, Merkel S, et al. D3 lymph 
node dissection in gastric cancer: Evaluation of postoperative mortality and complications. Surgery Today 2000;30:700-5.

10. Edwards P, Blackshaw GR, Lewis WG, et al. Prospective comparison of D1 vs modified D2 gastrectomy for carcinoma. Br J Cancer 2004;90:1888-92.

11. Wu CW, Hsiung CA, Lo SS, et al. Nodal dissection for patients with gastric cancer: a randomised controlled trial. Lancet Oncol 2006;7:309-15.

12. Marrelli D, Pedrazzani C, Neri A, et al. Complications after extended (D2) and superextended (D3) lymphadenectomy for gastric cancer: Analysis of potential risk factors. Ann Surg Oncol 2007;14:25-33.

13. Sano T, Sasako M, Yamamoto S, et al. Gastric cancer surgery: morbidity and mortality results from a prospective randomized controlled trial comparing D2 and extended para-aortic lymphadenectomy-Japan clinical oncology group study 9501. J Clin Oncol 2004;22:2767-73.

14. Yoshikawa T, Sasako M, Sano T, et al. Stage migration caused by D2 dissection with para-aortic lymphadenectomy for gastric cancer from the results of a prospective randomized controlled trial. Br J Surg 2006;93:1526-9.

15. Tsujinaka T, Sasako M, Yamamoto $S$, et al. Influence of overweight on surgical complications for gastric cancer: Results from a randomized control trial comparing D2 and extended para-aortic D3 lymphadenectomy (JCOG9501). Ann Surg Oncol 2007;14:355-61.

16. Sasako M, Sano T, Yamamoto S, et al. D2 lymphadenectomy alone or with para-aortic nodal dissection for gastric cancer. N Engl J Med 2008;359:453-62.

17. Pedrazzani, C. Functional outcomes after extended surgery for gastric cancer. Br J Surg 2011;98:246.

18. Sugimachi K, Kodama Y, Kumashiro R, et al. Critical evaluation of prophylactic splenectomy in total gastrectomy for the stomach cancer. Gan 1980;71:704-9.

19. Sugimachi K, Inokuchi K. Critical-evaluation of prophylactic splenectomy in total gastrectomy for stomach cancer. Gan No Rinsho 1984;30:1057-60.

20. Tamada R, Sugimachi K, Okamura T, et al. Evaluation of splenectomy in total gastrectomy for gastric cancer. Nihon Geka Gakkai Zasshi 1985;86:1124-7.

21. Yu W, Choi GS, Chung HY. Randomized clinical trial of splenectomy versus splenic preservation in patients with proximal gastric cancer. Br J Surg 2006;93:559-63.

22. Ito $\mathrm{H}$, Inoue $\mathrm{H}$, Odaka $\mathrm{N}$, et al. Prognostic impact of prophylactic splenectomy for upper-third gastric cancer: A cohort study. Anticancer Res 2013;33:277-82.
23. Ohkura Y, Haruta S, Shindoh J, et al. Efficacy of prophylactic splenectomy for proximal advanced gastric cancer invading greater curvature. World J Surg Oncol 2017;15:106.

24. Sano T, Sasako M, Mizusawa J, et al. Randomized controlled trial to evaluate splenectomy in total gastrectomy for proximal gastric carcinoma. Ann Surg 2017;265:277-83.

25. Imamura H, Kurokawa Y, Kawada J, et al. Influence of bursectomy on operative morbidity and mortality after radical gastrectomy for gastric cancer: results of a randomized controlled trial. World J Surg 2011;35:625-30.

26. Kayaalp C, Olmez A, Piskin T. Prophylactic bursectomy at radical gastrectomy for gastric cancer. Gastric Cancer 2011;14:399-400.

27. Fujita J, Kurokawa Y, Sugimoto T, et al. Survival benefit of bursectomy in patients with resectable gastric cancer: interim analysis results of a randomized controlled trial. Gastric Cancer 2012;15:42-8.

28. Hundahl, SA. The potential value of bursectomy in operations for trans-serosal gastric adenocarcinoma. Gastric Cancer 2012;15:3-4.

29. Eom BW, Joo J, Kim YW, et al. Role of bursectomy for advanced gastric cancer: Result of a case-control study from a large volume hospital. Eur J Surg Oncol 2013;39:1407-14.

30. Kochi M, Fujii M, Kanamori N, et al. D2 gastrectomy with versus without bursectomy for gastric cancer. Am J Clin Oncol 2014;37:222-6.

31. Sano T, Aiko T. New Japanese classifications and treatment guidelines for gastric cancer: revision concepts and major revised points. Gastric Cancer 2011;14:97-100.

32. Japanese Gastric Cancer Association. Japanese gastric cancer treatment guidelines 2010 (ver. 3). Gastric Cancer 2011;14:113-23.

33. Hartgrink HH, van de Velde CJ, Putter H, et al. Extended lymph node dissection for gastric cancer: Who may benefit? Final results of the Randomized Dutch Gastric Cancer Group Trial. J Clin Oncol 2004;22:2069-77.

34. Smith, DD, Schwarz RR, Schwarz RE. Impact of total lymph node count on staging and survival after gastrectomy for gastric cancer: data from a large USpopulation database. J Clin Oncol 2005;23:7114-24.

35. Schwarz RE, Smith DD. Clinical impact of lymphadenectomy extent in resectable gastric cancer of advanced stage. Ann Surg Oncol 2007;14:317-28.

36. Songun I, Putter H, Kranenbarg EM, et al. Surgical treatment of gastric cancer: 15 -year follow-up results of 
the randomised nationwide Dutch D1D2 trial. Lancet Oncol 2010;11:439-49.

37. Papenfuss WA, Kukar M, Oxenberg J, et al., Morbidity and mortality associated with gastrectomy for gastric cancer. Ann Surg Oncol 2014;21:3008-14.

38. Selby LV, Vertosick EA, Sjoberg DD, et al. Morbidity after total gastrectomy: Analysis of 238 patients. J Am Coll Surg 2015;220:863-71.e2.

39. Norero E, Vega EA, Diaz C, et al. Improvement in postoperative mortality in elective gastrectomy for gastric cancer: Analysis of predictive factors in 1066 patients from a single centre. Eur J Surg Oncol 2017;43:1330-6.

40. Cuschieri A, Fayers P, Fielding J, et al. Postoperative morbidity and mortality after D1 and D2 resections for gastric cancer: preliminary results of the MRC randomised controlled surgical trial. Lancet 1996;347:995-9.

41. Bonenkamp JJ, Hermans J, Sasako M, et al. Extended lymph-node dissection for gastric cancer. N Engl J Med 1999;340:908-14.

42. Pasquer A, Renaud F, Hec F, et al. Is centralization needed for esophageal and gastric cancer patients with low operative risk? A nationwide study. Ann Surg 2016;264:823-30.

43. Watanabe M, Miyata $H$, Gotoh $M$, et al. Total gastrectomy risk model: data from 20,011 Japanese patients in a nationwide internet-based database. Ann Surg 2014;260:1034-9.

44. Kunisaki C, Miyata H, Konno H, et al. Modeling preoperative risk factors for potentially lethal morbidities using a nationwide Japanese web-based database of patients undergoing distal gastrectomy for gastric cancer. Gastric Cancer 2017;20:496-507.

45. Degiuli M, Sasako M, Ponti A, et al. Randomized clinical trial comparing survival after D1 or D2 gastrectomy for gastric cancer. Br J Surg 2014;101:23-31.

46. Global Burden of Disease Cancer Collaboration, Fitzmaurice C, Allen C, Barber RM, et al. Global, regional, and national cancer incidence, mortality, years of life lost, years lived with disability, and disability-adjusted life-years for 32 cancer groups, 1990 to 2015: A systematic analysis for the global burden of disease study. JAMA Oncol 2017;3:524-48.

47. Ferro A, Peleteiro B, Malvezzi M, et al. Worldwide trends in gastric cancer mortality (1980-2011), with predictions to 2015, and incidence by subtype. Eur J Cancer 2014;50:1330-44.

48. Colquhoun A, Arnold M, Ferlay J, et al. Global patterns of cardia and non-cardia gastric cancer incidence in 2012.
Gut 2015;64:1881-8.

49. Plummer M, Franceschi S, Vignat J, et al. Global burden of gastric cancer attributable to Helicobacter pylori. Int J Cancer 2015;136:487-90.

50. Powell J, McConkey CC, Gillison EW, Spychal RT. Continuing rising trend in oesophageal adenocarcinoma. Int J Cancer 2002;102:422-7.

51. Crew KD, Neugut AI. Epidemiology of upper gastrointestinal malignancies. Semin Oncol 2004;31:450-64.

52. Wang Z, Graham DY, Khan A, et al. Incidence of gastric cancer in the USA during 1999 to 2013: a 50-state analysis. Int J Epidemiol 2018;47:966-75.

53. Hiroi S, Sugano K, Tanaka S, Kawakami K. Impact of health insurance coverage for Helicobacter pylori gastritis on the trends in eradication therapy in Japan: retrospective observational study and simulation study based on realworld data. BMJ Open 2017;7:e015855.

54. Nashimoto A, Akazawa K, Isobe $Y$, et al. Gastric cancer treated in 2002 in Japan: 2009 annual report of the JGCA nationwide registry. Gastric Cancer 2013;16:1-27.

55. Maruyama M, Takeshita K, Endo M, et al. Clinicopathological study of gastric carcinoma in highand low-mortality countries: Comparison between Japan and the United States. Gastric Cancer 1998;1:64-70.

56. Japanese Gastric Cancer Association Registration Committee, Maruyama K, Kaminishi M, et al. Gastric cancer treated in 1991 in Japan: data analysis of nationwide registry. Gastric Cancer 2006;9:51-66.

57. Watabe H, Mitsushima T, Yamaji Y, et al. Predicting the development of gastric cancer from combining Helicobacter pylori antibodies and serum pepsinogen status: a prospective endoscopic cohort study. Gut 2005;54:764-8.

58. Hamashima C, Shibuya D, Yamazaki H, et al. The Japanese guidelines for gastric cancer screening. Jpn J Clin Oncol 2008;38:259-67.

59. Yanaoka K, Oka M, Yoshimura N, et al. Risk of gastric cancer in asymptomatic, middle-aged Japanese subjects based on serum pepsinogen and Helicobacter pylori antibody levels. Int J Cancer 2008;123:917-26.

60. Aikou S, Ohmoto Y, Gunji T, et al. Tests for serum levels of trefoil factor family proteins can improve gastric cancer screening. Gastroenterology 2011;141:837-45.

61. Gotoda T, Ishikawa H, Ohnishi H, et al. Randomized controlled trial comparing gastric cancer screening by gastrointestinal X-ray with serology for Helicobacter pylori and pepsinogens followed by gastrointestinal 
endoscopy. Gastric Cancer 2015;18:605-11.e1.

62. Hamashima C, Systematic Review Group and Guideline Development Group for Gastric Cancer Screening Guidelines. Systematic Review, and G. Guideline Development Group for Gastric Cancer Screening, Update version of the Japanese Guidelines for Gastric Cancer Screening. Jpn J Clin Oncol 2018;48:673-83.

63. Inoue $M$, Tsugane $S$. Epidemiology of gastric cancer in Japan. Postgrad Med J 2005;81:419-24.

64. Olch PD. Johann von Mikulicz-Radecki. Ann Surg 1960;152:923-6.

65. Groves EW. On the radical operation for cancer of the pylorus: with especial reference to the advantages of the two-stage operation and to the question of removal of the associated lymphatics. Br Med J 1910;1:366-70.

66. Brunschwig A. Pancreato-total gastrectomy and splenectomy for advanced carcinoma of the stomach. Cancer 1948;1:427-30.

67. McNEER G, James A. Resection of stomach and adjacent organs in continuity for advanced cancer. Cancer 1948;1:449-54.

68. Lawrence $W \mathrm{Jr}, \mathrm{McNeer} \mathrm{G}$. An analysis of the role of radical surgery for gastric cancer. Surg Gynecol Obstet 1960;111:691-6.

69. Cattell RB, Mosely CH. Combined resection of the stomach and transverse colon for carcinoma; report of two cases. Lahey Clin Bull 1946;4:238-41.

70. Pack GT. Radical surgical treatment of gastric cancer. Calif Med 1947;66:120-4.

71. Pack GT. The radical surgical treatment of gastric cancer. J Natl Cancer Inst 1947;7:337-44.

72. Pack GT, Mc NG. End results in the treatment of cancer of the stomach; analysis of 795 cases. Surgery 1948;24:769-78.

73. Pack GT, Mc NG. Surgical treatment of cancers of the gastric cardia. Surgery 1948;23:976-1019.

74. Pack GT, Mc NG. Palliative operations for gastric cancer. Rev Gastroenterol 1949;16:291-321.

75. Appleby LH. The coeliac axis in the expansion of the operation for gastric carcinoma. Cancer 1953;6:704-7.

76. McNeer G, Bowden L, Booner RJ, et al. Elective total gastrectomy for cancer of the stomach: end results. Ann Surg 1974;180:252-6.

77. Lortat-Jacob J, Giuli R, Estenne B, et al. Value of total gastrectomy for treatment of cancers of the stomach. Study of 482 radical operations. Chirurgie 1975;101:59-67.

78. Gennari L, Bozzetti F, Bonfanti G, et al. Subtotal versus total gastrectomy for cancer of the lower two-thirds of the stomach: A new approach to an old problem. Br J Surg 1986;73:534-8.

79. Gouzi JL, Huguier M, Fagniez PL, et al. Total versus subtotal gastrectomy for adenocarcinoma of the gastric antrum. A French prospective controlled study. Ann Surg 1989;209:162-6.

80. Bozzetti F, Marubini E, Bonfanti G, et al. Subtotal versus total gastrectomy for gastric cancer: five-year survival rates in a multicenter randomized Italian trial. Italian Gastrointestinal Tumor Study Group. Ann Surg 1999;230:170-8.

81. Cuschieri A, Weeden S, Fielding J, et al. Patient survival after D1 and D2 resections for gastric cancer: long-term results of the MRC randomized surgical trial. Surgical Cooperative Group. Br J Cancer 1999;79:1522-30.

82. Begg CB, Cramer LD, Hoskins WJ, et al. Impact of hospital volume on operative mortality for major cancer surgery. JAMA 1998;280:1747-51.

83. Birkmeyer JD, Siewers AE, Finlayson EV, et al. Hospital volume and surgical mortality in the United States. N Engl J Med 2002;346:1128-37.

84. Dikken JL, van Sandick JW, Allum WH, et al. Differences in outcomes of oesophageal and gastric cancer surgery across Europe. Br J Surg 2013;100:83-94.

85. Kondo T. An experiment in gastric cancer surgery (in Japanese). Nihon Gekagakkai Zasshi 1899;1:234-52.

86. Kuru M. Statistical consideration of radical surgery for gastric cancer (in Japanese). Rinshou IIgaku 1935;23:390-6.

87. Kajitani T. Lymph node metastasis of gastric cancer (in Japanese). Nihon Gekagakkai Zassi 1944;45:15-6.

88. Kajitani T, Hoshino T. An experience of pancreatoduodenectomy (in Japanese). Rinshougeka 1952;7:231-5.

89. Jinnai D. Extended radical operation of gastric cancer, with special emphasis on the lymph node dissection (in Japanese). Gekashinryou 1961;3:556.

90. Ohashi I, Takagi K, Konishi T, et al. 5-year survivors of gastric cancer patients with para-aortic lymph node metastasis (in Japanese). Nihon Shoukakigeka Gakkaishi 1976;9:507-12.

91. Kajitani T, Takagi K, Ohashi I. Radical surgery for gastric cancer (dissection of the left side) (in Japanese). Gekashinryou 1981;23:412-7.

92. Ohta K, Nishi M, Nakajima T, et al. Indications for total gastrectomy combined with pancreaticosplenectomy in the treatment of middle gastric cancer. Nihon Geka Gakkai Zasshi 1989;90:1326-30.

93. Maruyama K, Sasako M, Kinoshita T, et al. Pancreas- 
preserving total gastrectomy for proximal gastric cancer. World J Surg 1995;19:532-6.

94. Furukawa H, Hiratsuka M, Ishikawa O, et al. Total gastrectomy with dissection of lymph nodes along the splenic artery: a pancreas-preserving method. Ann Surg Oncol 2000;7:669-73.

95. Sasako M, Sakuramoto S, Katai H, et al. Five-Year outcomes of a randomized phase III trial comparing adjuvant chemotherapy with S-1 versus surgery alone in stage II or III gastric cancer. J Clin Oncol 2011;29:4387-93.

96. Kurokawa Y, Doki Y, Mizusawa J, et al. Bursectomy versus omentectomy alone for resectable gastric cancer (JCOG1001:a phase 3, open-label, randomised controlled trial. Lancet Gastroenterol Hepatol 2018;3:460-8.

97. Shirasaka T, Aiba K, Araki H, et al. Combination therapy of continuous venous infusion (CVI) of 5-FU and low dose consecutive cisplatin (CDDP), and the new oral anticancer drug S-1 for advanced gastro-intestinal cancer. Gan To Kagaku Ryoho 1999;26:456-66.

98. Maehara Y, Sugimachi K, Kurihara M, et al. Clinical evaluation of S-1, a new anticancer agent, in patients with advanced gastrointestinal cancer. Gan To Kagaku Ryoho 1999;26:476-85.

99. Sakuramoto S, Sasako M, Yamaguchi T, et al. Adjuvant chemotherapy for gastric cancer with S-1, an oral fluoropyrimidine. N Engl J Med 2007;357:1810-20.

100. Ychou M, Boige V, Pignon JP, et al. Perioperative chemotherapy compared with surgery alone for resectable gastroesophageal adenocarcinoma: An FNCLCC and FFCD multicenter phase III trial. J Clin Oncol 2011;29:1715-21.

101. Noh SH, Park SR, Yang HK, et al. Adjuvant capecitabine plus oxaliplatin for gastric cancer after D2 gastrectomy (CLASSIC:5-year follow-up of an open-label, randomised phase 3 trial. Lancet Oncol 2014;15:1389-96.

102. Tsuburaya A, Yoshida K, Kobayashi M, et al. Sequential paclitaxel followed by tegafur and uracil (UFT) or S-1 versus UFT or S-1 monotherapy as adjuvant chemotherapy for $\mathrm{T} 4 \mathrm{a} / \mathrm{b}$ gastric cancer (SAMIT:a phase 3 factorial randomised controlled trial. Lancet Oncol 2014;15:886-93.

103. Tanabe K, Fujii M, Nishikawa K, et al. Phase II/III study of second-line chemotherapy comparing irinotecanalone with S-1 plus irinotecan in advanced gastric cancer refractory to first-line treatment with S-1 (JACCRO GC05). Ann Oncol 2015;26:1916-22.

104. Ryu MH, Baba E, Lee KH, et al. Comparison of two different S-1 plus cisplatin dosing schedules as first-line chemotherapy for metastatic and/or recurrent gastric cancer: a multicenter, randomized phase III trial (SOS). Ann Oncol 2015;26:2097-101.

105.Fujitani K, Yang HK, Mizusawa J, et al. Gastrectomy plus chemotherapy versus chemotherapy alone for advanced gastric cancer with a single non-curable factor (REGATTA:a phase 3, randomised controlled trial. Lancet Oncol 2016;17:309-18.

106. Yoshikawa T, Morita S, Tanabe K, et al. Survival results of a randomised two-by-two factorial phase II trial comparing neoadjuvant chemotherapy with two and four courses of S-1 plus cisplatin (SC) and paclitaxel plus cisplatin (PC) followed by D2 gastrectomy for resectable advanced gastric cancer. Eur J Cancer 2016;62:103-11.

107. Hironaka S, Sugimoto N, Yamaguchi K, et al. S-1 plus leucovorin versus $\mathrm{S}-1$ plus leucovorin and oxaliplatin versus $\mathrm{S}-1$ plus cisplatin in patients with advanced gastric cancer: a randomised, multicentre, open-label, phase 2 trial. Lancet Oncol 2016;17:99-108.

108. Shitara K, Chin K, Yoshikawa T, et al. Phase II study of adjuvant chemotherapy of S-1 plus oxaliplatin for patients with stage III gastric cancer after D2 gastrectomy. Gastric Cancer 2017;20:175-81.

109. Ito S, Sano T, Mizusawa J, et al. A phase II study of preoperative chemotherapy with docetaxel, cisplatin, and S-1 followed by gastrectomy with D2 plus para-aortic lymph node dissection for gastric cancer with extensive lymph node metastasis: JCOG1002. Gastric Cancer 2017;20:322-31.

110. Kimura Y, Fujii M, Masuishi T, et al. Multicenter phase II study of trastuzumab plus S-1 alone in elderly patients with HER2-positive advanced gastric cancer (JACCRO GC-06). Gastric Cancer 2018;21:421-7.

111. Miura Y, Sukawa Y, Hironaka S, et al. Five-weekly S-1 plus cisplatin therapy combined with trastuzumab therapy in HER2-positive gastric cancer: a phase II trial and biomarker study (WJOG7212G). Gastric Cancer 2018;21:84-95.

112.Bang YJ, Van Cutsem E, Feyereislova A, et al. Trastuzumab in combination with chemotherapy versus chemotherapy alone for treatment of HER2-positive advanced gastric or gastro-oesophageal junction cancer (ToGA:a phase 3, open-label, randomised controlled trial. Lancet 2010;376:687-97.

113. Fuchs CS, Tomasek J, Yong CJ, et al. Ramucirumab monotherapy for previously treated advanced gastric or gastro-oesophageal junction adenocarcinoma (REGARD:an international, randomised, multicentre, 
placebo-controlled, phase 3 trial. Lancet 2014;383:31-9.

114. Wilke H, Muro K, Van Cutsem E, et al. Ramucirumab plus paclitaxel versus placebo plus paclitaxel in patients with previously treated advanced gastric or gastro-oesophageal junction adenocarcinoma (RAINBOW:a double-blind, randomised phase 3 trial. Lancet Oncol 2014;15:1224-35.

115. Hur H, Lee HY, Lee HJ, et al. Efficacy of laparoscopic subtotal gastrectomy with D2 lymphadenectomy for locally advanced gastric cancer: the protocol of the KLASS-02 multicenter randomized controlled clinical trial. BMC Cancer 2015;15:355.

116. Hu Y, Huang C, Sun Y, et al. Morbidity and mortality of laparoscopic versus open D2 distal gastrectomy for advanced gastric cancer: A randomized controlled trial. J Clin Oncol 2016;34:1350-7.

117. Kim W, Kim HH, Han SU, et al. Decreased morbidity of laparoscopic distal gastrectomy compared with open distal gastrectomy for stage I gastric cancer: short-term outcomes from a multicenter randomized controlled trial (KLASS-01). Ann Surg 2016;263:28-35.

118.Zhang CD, Yamashita H, Zhang S, et al. Reevaluation

Cite this article as: Zhang $\mathrm{CD}$, Yamashita $\mathrm{H}$, Seto Y. Gastric cancer surgery: historical background and perspective in Western countries versus Japan. Ann Transl Med 2019;7(18):493. doi: $10.21037 /$ atm.2019.08.48 of laparoscopic versus open distal gastrectomy for early gastric cancer in Asia: A meta-analysis of randomized controlled trials. Int J Surg 2018;56:31-43.

119. Fujii K, Sonoda K, Izumi K, et al. T lymphocyte subsets and Th1/Th2 balance after laparoscopy-assisted distal gastrectomy. Surg Endosc 2003;17:1440-4.

120. Yoshikawa T, Cho H, Rino Y, et al. A prospective feasibility and safety study of laparoscopy-assisted distal gastrectomy for clinical stage I gastric cancer initiated by surgeons with much experience of open gastrectomy and laparoscopic surgery. Gastric Cancer 2013;16:126-32.

121. Inaki N, Etoh T, Ohyama T, et al. A multi-institutional, prospective, phase II feasibility study of laparoscopyassisted distal gastrectomy with D2 lymph node dissection for locally advanced gastric cancer (JLSSG0901). World J Surg 2015;39:2734-41.

122. Nakamura K, Katai H, Mizusawa J, et al. A phase III study of laparoscopy-assisted versus open distal gastrectomy with nodal dissection for clinical stage IA/IB gastric cancer (JCOG0912). Jpn J Clin Oncol 2013;43:324-7. 